\title{
DETERMINING TRAVEL DELAY OF VEHICLES QUEUE AT A TRAFFIC SIGNAL
}

\section{Penentuan Tundaan Perjalanan Pada Antrian Kendaraan di Sebuah Sinyal Lalu Lintas}

\author{
Setiyo Daru Cahyono ${ }^{1}$, Tomi Tristono ${ }^{2 *}$, Seno Aji ${ }^{3}$, Pradityo Utomo ${ }^{4}$ \\ 1,3 Civil Engineering Departement, University of Merdeka Madiun \\ ${ }^{2,4}$ Informatics Management Departement, University of Merdeka Madiun \\ Serayu Road 79, Madiun City - East Java, 63133, Indonesia \\ e-mail: 1 cahyono.ds@gmail.com ; 2*tomitristono@gmail.com ; 3 abiseno40@gmail.com ; \\ 4pradityou@gmail.com \\ Corresponding author*
}

\begin{abstract}
Mathematical modelling assumes that the vehicle's volume has a uniform pattern. Due to traffic lights settings, the number of vehicles quеuе grows linearly. The reality, the stochastic arrivals of the vehicles could be (1) in the randomized arrivals, (2) in the form of groups/ platoon, or (3) in the mixed arrivals. It is observed that the arrival of the vehicles in the queue tends to have a normal pattern. The objective of this research is to study the implications of the arrival categories to the travel delay. For simulation, it uses the numerical method referring to the real state. The result indicates, determining travel delay become precise for all vehicles. It is due to the travel delay formula is represented as a discrete function. The arrival time, departure time, and stop time for each vehicle at the signalized intersection are recorded in the device.
\end{abstract}

Keywords: Randomized arrivals, groups/ platoon arrivals, normal arrivals pattern, travel delay. 


\section{PRELIMINARY}

This study reviews a vehicle queue that arises due to traffic light settings. The arrival process could be classified into three categories, i.e., (1) random arrivals, (2) group/platoon arrivals, or (3) mixed arrivals [1]. In the first category, the vehicles arrive at the signalled intersection randomly. The second, the group/ platoon arrivals may exist in urban areas due to the traffic light setting at the upstream intersection, which is adjacent, and the scheduling is not coordinated. The third is mixed arrivals. Here, it could be categorized as the intermediate state between both purely random and groups/platoon arrivals.

In mathematical modelling, it usually assumes the arrival process follows a uniform pattern [2]. So while in the time interval of the red signal, the number of vehicles grows linearly [3]. In this case, the flow of the vehicles is seen as a continuous function. This is an excellent method for estimating the number of queues of vehicles due to traffic light settings. However, the determination becomes difficult to find out the travel delay [3]. The reason, the arrival of vehicles in the travel delay formula must be represented as a discrete function. The number of vehicles is not a continuous function.

Based on the empirical data, the volume of vehicles passing on the road at the same time interval during a day is likely to be deterministic. The traffic flow at midnight is very low and reaches its peak during the day [4]. This is related to human activities that tend to repeat daily. If this is related to the category of the arrival process, this means that it is not absolutely random.

The departure rate of the vehicles when the green signal lights up tends to be negative exponential [5]. The number of service channels corresponds to the number of road lanes. In this scenario, the vehicle departs to leave the intersection in a sequence of discrete-time intervals. For example, it has passed six vehicles in the first step. This is followed by the second step with five vehicles, and so on until the green signal ends. Each step is a time interval of three seconds. This is similar to the statistical concept of queuing. But, in the flow of vehicle traffic, this service style must be interpreted somewhat differently [5].

A lot of researchers use M/M/1 queueing systems. They assume the arrival of vehicles has a Poisson distribution. The reason is that the system meets the following state: (1). The total number of vehicles passing on the road is very large, (2). A single-vehicle uses a tiny percentage of the road resources, and (3). The pattern of vehicle movement on the road is independently made by each driver [1].

In this research, we observed the number of vehicles passing on the road at the specified time interval. This method may differ from the concept of probability of arrival according to queuing theory. This adjusts to the requirement of sensors to calculate the actual number of vehicles passing. The time interval has a short duration. It may consist of several seconds and in the chronological order [6]. While using this method, the arrival of a vehicle in several traffic light cycles may be considered as the normal pattern. The curve tends to be symmetric, and the variance differs significantly from the mean of the data [7]. In the Poisson distribution, the mean value is equal to its variance unless there is a specific treatment, as an example for a race.

The objective of this research is to study in-depth the effect of the arrival of vehicles that are considered to have a normal pattern. We create an algorithm of the arrival of vehicles and the implication of its travel delays. More specifically, while it is in the randomized arrivals and when it is in the form of groups/ platoon. The simulation uses this algorithm allows estimation of the performance of an intersection in several different conditions, allows the study of a long time frame in a shorter time, and costs less.

There is an advantage of assuming the arrival of a vehicle with a normal pattern. This assumption is a precise approximation for arrival processes in real systems. Among them is the formulation of a travel delay. This is very useful for classifications that represent the performance of the road. Estimation of the Level of Performance (LoP) based on the assumption that the arrival has a uniform pattern is less accurate [4]. So, this is sometimes different from reality.

While the regular state, the platoon model in groups of vehicles passing on the road has a normal pattern. It has a higher peak and a wider deviation. The size of the pattern curve of the platoon model is bigger than the random arrival.

Transportation experts have been done many of the previous research on travel delays. F. Viti [4] had talked about the level of randomness in the traffic flows. They observed at the same time interval in a day of the days in which the human activities are regularly repeating. N. Mufidah [5] has written about modelling of motor vehicle queue using M/M/1 queue models in Yogyakarta, A. Narendra, and A. 
Budiwirawan [8], have researched how to handle the delay of movement of an intersection that has four arms. M. B. Asih, and I. Muthohar [9] had talked about the efforts to solve traffic problems due to high sideroad activity using delays analysis. R. Kurniawan and R. A. Al-Hasibi [12] investigated the concept of adaptive traffic control systematically. It synchronized with the density of road traffic. They claimed that the solution could minimize the duration of the waiting time of vehicles. G. W. Hamidi, A. Frederika, \& P. K. Winaya [14] had analyzed the travel cost due to traffic delays. They said that traffic delays had an impact on travel costs. M. I.Mujahidin, had analyzed the travel delay, and this was connected to the fuel consumption due to bottleneck when flyover development in Palur area. They concluded that the higher the delay value and the longer the queue, the greater the fuel consumption. None of the previous researches studies in-depth the effect of the arrival of vehicles that considered to have a normal pattern and used a discrete function.

This paper is organized as the following. In Section I, we write the preliminary. This section contains the rationale and objective of the research. In Section II, we discuss the research method. The results and discussion are written in Section III. In Section IV, we write conclusions.

\section{RESEARCH METHOD}

First, we introduced the mathematical concept of the arrival of vehicles with a normal pattern. Also, we explain the possibility of real vehicle arrival. It also presented the concept of customer service and travel delays.

This research uses a numerical method for the simulation that presents the queue of vehicles due to traffic light settings. We compare the queue whose arrival has a normal pattern with a uniform distribution. Furthermore, it is about the travel delays.

\subsection{Mathematical Model}

In a short time interval, the queue system has the stochastic arrivals. The arrival of vehicles in the regular state can be a non-integer value. The number of vehicle queues is X. It is written in Eq. (1).

$$
X=d . t+b
$$

The non-negative arrival of vehicle rate per step of time is " $d$ ", $d \in R$. The value of " $d$ " is not constant. It has a normal pattern in the fixed time interval. The density interval value is $0 \leq d \leq 4$ while in the randomized arrival of 2,500 PCUs/ hour. " $\mathrm{t}$ " is the step of the time interval of $\Delta \mathrm{t}$. In this time, it uses three seconds. " $b$ " is the number of vehicles left that have not passed in the previous traffic lights cycle.

The arrival of the vehicles can have a fractional value. In transportation engineering, experts measure the level of vehicles passing through the road using the standard metric "Passenger Car Unit" (PCU) [10], [11]. The classifications are as follows: a motorcycle (MC) is $0.4 \mathrm{PCU}$, a low vehicle (LV)/a passenger car is 1 $\mathrm{PCU}$, and a heavy vehicle (HV) is $1.3 \mathrm{PCU}$, while unmotorized vehicles are ignored.

Fig. 1 is for the vehicle's arrival around 2,500 PCUs/hour. It is obtained from observational records of the empirical data. For the randomized arrivals, the most arrivals at three-second intervals $a_{\max }$ are 4 PCUs. When the flow of the vehicles is in the form of a platoon, the value of $a_{\max }$ is equal to the maximum capacity of the road. In this case, $a_{\max }$ is greater than 4 PCUs.

\subsection{The Normal Pattern of Arrival of Vehicles}

The normal distribution is also called the Gauss distribution. It is written $N\left(\mu, \sigma^{2}\right)$. The parameter $\mu$ states the mean, median, and mode. The second parameter $\sigma$ denotes deviations. The curve model has a bell pattern. The skewness value is zero [7].

The arrivals of vehicles in the queue is measured at three-second time intervals. The duration of a traffic light cycle is set consisting of many multiplications of a three-second time interval. The observations made on several traffic light cycles present regular pattern repetition. The arrival of the vehicles could be a non-negative of the transverse wave. 
About a 9-minute simulation is displayed in Fig. 2. It employs any empirical data. It shows that the arrival of vehicles has a normal distribution. It looks like a bell. The highest frequency is the arrivals which approach to the mean and the mode. The arrival of vehicles in large and small quantities or the number larger and smaller than the mean, its occurrence frequency is low.

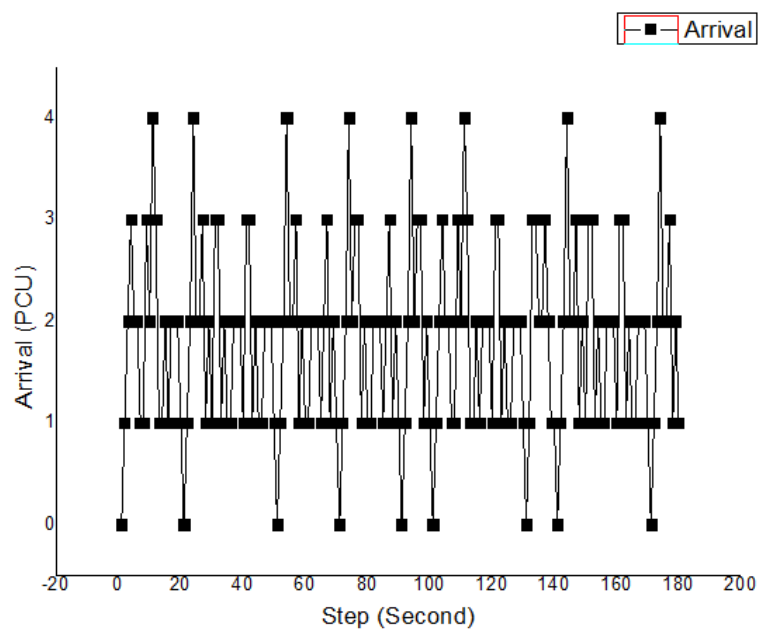

Fig. 1. The real arrivals of vehicles which considered have a normal pattern in the eight cycles of traffic lights. It is a randomized arrival. The traffic volume is 2,500 PCUs/ hour

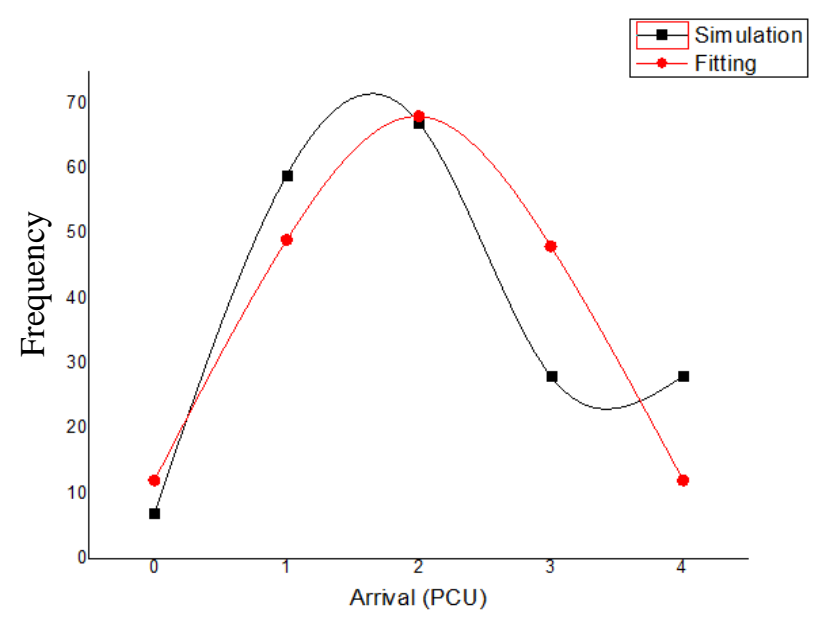

Fig. 2. The simulation of the arrival of the vehicles of eight traffic light cycles or about 177 time steps. Each cycle duration is 63 seconds. The traffic lights apply a fixed time strategy. This vehicle arrival model is considered to have a normal pattern rather than the Poisson distribution. Kolmogorov-Smirnov normality test showed its significance is 90\%. The mean is 2.1 PCUs, and the variance is 1.1 PCU

\subsection{The Service Concept}

The amount of the service channels concept corresponds to the number of road lanes. This assumption is based on a non-lane-based vehicles traffic movement. The queue structure system is the Multi Channels-Single Phase. It arises when there are two or more service facilities/ lanes flowed by a single queue. Its vehicles queue has an infinite population source [7].

The system has an FCFS (First Come First Serve) queue discipline. This means that the person/ vehicle that comes first is served first, too. The vehicles that arrived are allowed to move to another lane.

The number of lanes depends on the width of the road. As shown in Fig. 3., the vehicle that came later was allowed to move to another lane if it was empty. The simulation implements three lanes/ channels. They are assumed not to be able to overtake another vehicle at the intersection area. 


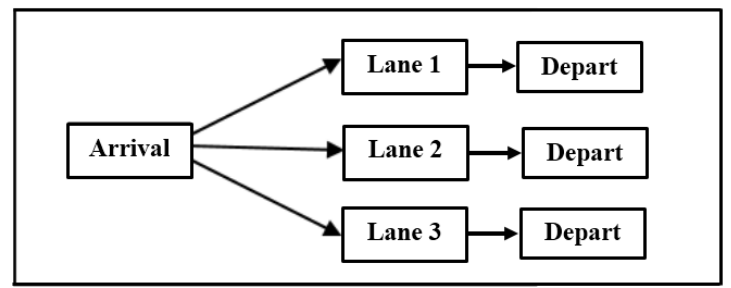

Fig. 3. For non-lane-based traffic flows, the queue system is identical to the implementation of service concept with multi-channels and single phase. The number of channels corresponds to the number of lanes of the road

\subsection{The Definition of TheTravel Delay}

The travel delay is the difference in travel time from a starting point to the point of destination between the free state flow and the blocked current [13]. Delay is a significant variable to determine the quality of traffic. The value of travel delay is equivalent to the level of congestion on the road segment. The Level of Service (LoS) index uses the travel delay interval as the measurement indicator.

The vehicles that arrive at the intersection when the red signal lights up, they must stop for a while. They may depart from the intersection when the green signal is on. The setting of the traffic lights always causes travel delays. However, this promises travel safety, share a fair travel time for all road users, and also efficiency reasons.

Refer to Fig. 4., the travel delay begins at the arrival of each vehicle and when it starts to stop. The travel delay is counted until the vehicle moves forward again at $t_{0}$ when the green signal lights up. The time step starts at $t_{d}$ when the red signal lights up and move right until the departure of the vehicle to leave away the intersection.

According to Kurniawan [12], the traffic lights schedule cause the waiting time for all vehicles arriving at the time $t_{d}$ is $\omega\left(t_{d}\right)$.

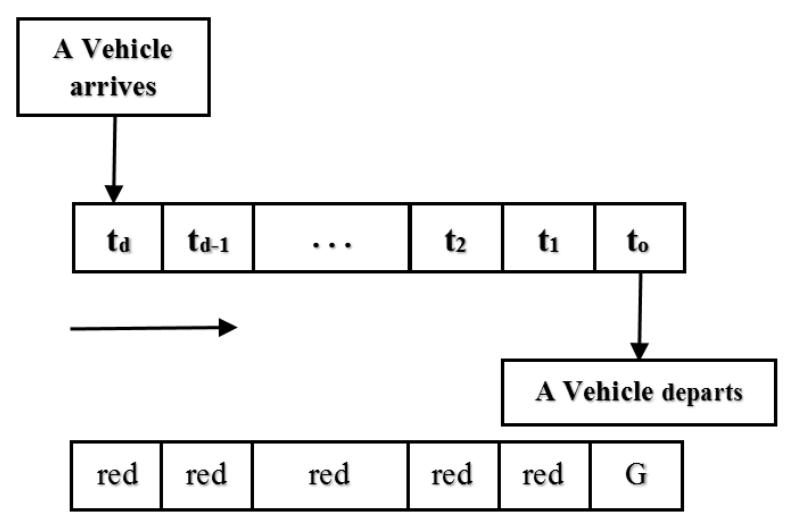

Fig. 4. A vehicle arrives while the red signal of traffic lights and departs when the green signal. It is the travel delay concept. The letter $\mathbf{G}$ stands for green signal traffic lights. The direction of the arrow shows the decrease in each unit of time from arrival to the departure of a vehicle

$$
\omega\left(t_{d}\right)=d\left(t_{d}\right) \times\left(t_{o}-t_{d}\right)
$$

Where $d\left(t_{d}\right)=$ traffic volume at the time $t_{d}, t_{o}=$ the time of the vehicle's departure, and $t_{d}=$ the time when the vehicles arrived at the intersection.

$$
\hat{\omega}\left(t_{o}\right)=\sum_{t=t_{o}-T}^{t_{o}-1} d(t) \times\left(t_{o}-t\right)
$$


Where $d(t)=$ traffic volume while the time $t$. The total of the waiting time of all vehicles arriving when the red signals turn on is $\hat{\omega}\left(t_{o}\right)$. T is the total red signal time interval in a cycle of the traffic light.

The performance of a signalized intersection in transportation engineering is assessed by the delay of the traffic flow [10], [11]. The indicators are presented using the Level of Service (LoS) index. While the average travel delay of all vehicles that cross an intersection is low, intersection performance is better. There are six types of travel delay time interval categories. It is shown in Table 1 . When the average travel delay for all vehicles is less than or equal to 5 seconds/ PCU, the category is A, which is the best. This reflects the flow of traffic smoothly, and there are no obstacles.

On the contrary, when the category is F, which is the worst. This means that severe congestion occurs and the flow of vehicles has exceeded the intersection capacity. While the category is $\mathrm{C}$, which is the in the middle state. Traffic flow is smooth, but the volume of vehicles passing is approaching the maximum intersection capacity.

Table 1. Los Index Refer On The Traffic Delay

\begin{tabular}{|cc|}
\hline $\begin{array}{c}\text { Level of Service (LoS) } \\
\text { Index }\end{array}$ & $\begin{array}{c}\text { Travel Delay } \\
\text { (Seconds/ PCU) }\end{array}$ \\
\hline A & $\leq 5,0$ \\
B & $5,1-15,0$ \\
C & $15,1-25,0$ \\
D & $25,1-40,0$ \\
E & $40,1-60,0$ \\
F & $\geq 60,1$ \\
\hline Cited from Tamin [10] \&IHCM [11] & \\
\hline
\end{tabular}

\section{RESULTS AND DISCUSSIONS}

This section presents the algorithm, the case test and the device used for the implementation of this system.

\subsection{The Algorithm of The Travel Delay Determination}

Each vehicle has a unique $t_{d}$ as the delay time value. The relation is $V(i, j) \rightarrow t_{d}(i, j)$. For simplification, we describe each vehicle $V(i, j)$ that crosses the intersection with 1 PCU. This is a rounding number, so that determining the delay time is easy. So as a consequence, we can illustrate as the homogeneous traffic flow. One PCU represented using a single-vehicle.

The following is the declaration refers to Fig. 5. No previous intersection is adjacent. The vehicles arrive entirely with a random pattern. The vehicles arriving and stopping at the intersection in step 1 are three PCUs. Sequentially in step 2 and step 3 are two vehicles arrived. In step 4, step 5, step 6, and step 7 arrive $3,1,2$, and 4, respectively. Step 5, step 6, and step 7 when a red signal, they do not appear in the figure. 


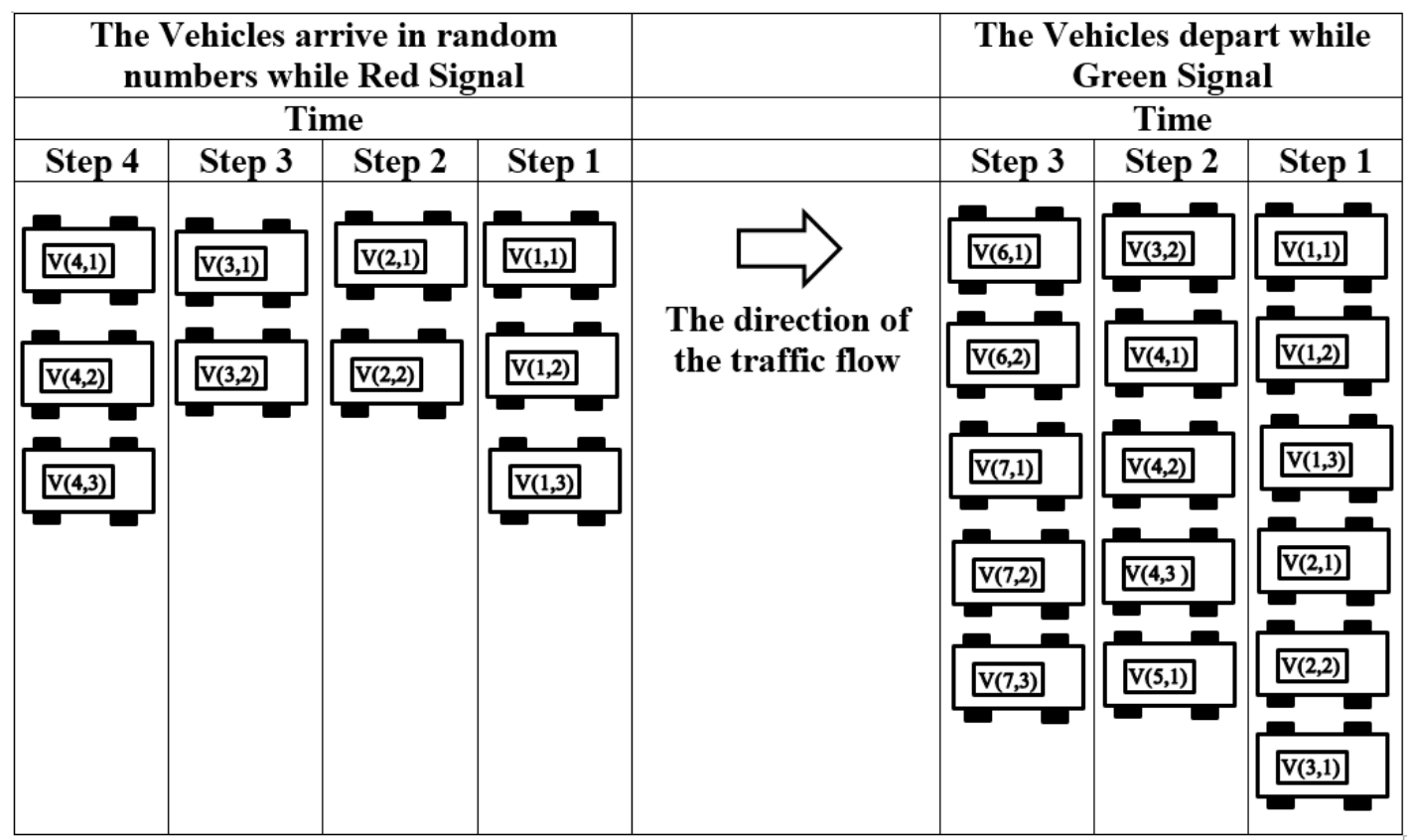

Fig. 5. The travel delay scenario while the vehicles arrive in random numbers and leave the intersections with negative exponential patterns

It indicates that the maximum capacity of vehicles passing on the road is six vehicles every three seconds. When referring to the arrival, the traffic flow has not reached the saturation point, and there is no congestion. So that we assume, there are no vehicles left that have not crossed at the previous traffic light cycle [10],[11]. The travel delay is zero for the vehicles that arrive when the green signal is on.

The different states are found when the peak hours in the daytime. The Degree of Saturation (DS) approaches 1. As we know, the Degree of Saturation of a road is at an interval of $0<\mathrm{DS} \leq 1$. There are many vehicles left that have not crossed the intersection at the previous traffic light cycle. The congestion occurs. The vehicle stops at step 1 when the red signal cannot cross the signal in step 1 while the green signal is on. They must wait for the vehicles from the previous cycle to cross the intersection first. This situation has the potential to create a high travel delay.

When in the form of groups/ platoons, the vehicle arrives in large numbers at several consecutive time steps. The arrival is zero in some other time steps. It becomes fluctuating, and the pattern of the arrivals is not evenly distributed. The platoon can arrive when the red signal or green signal is on.

\subsection{Test}

The following is a numerical simulation of the travel delay. The vehicles that are in the form of mixed or intermediate arrivals between groups/ platoon and random are not illustrated. Simulations of the model were done in three different situations. The first stage is for the vehicles that have a random arrival. Second, namely, the vehicles that are arrived in the form of a group or platoon. They arrive at the beginning of the traffic lights cycle. It means when the signal lights start-up red. The third is the vehicles that are arrived in the form of a group or platoon. They arrive when the traffic lights immediately turned green. Data retrieved and compared. The objective of the test is to determine the delay in these three different situations.

In Fig. 6., we show three types of travel delay curves. Both red and blue curves when they arrive in groups/ platoon which often happens in cities. The red curve reflects a high travel delay. This often happens in urban areas when a schedule of two or more adjacent intersections is not coordinated. The vehicles that pass become frequently stop when meeting traffic lights. Besides the delay being high, travel also becomes uncomfortable.

When the traffic lights schedule is coordinated, the delay becomes low or even close to zero. This is shown in the blue curve. The delay is low, and the travel of the vehicles become comfortable. In this state, the vehicle rarely stops because of the adjacent red signal.

The black curve represents a random arrival. This arrival is more common outside the city where signalized intersections are very rare. 


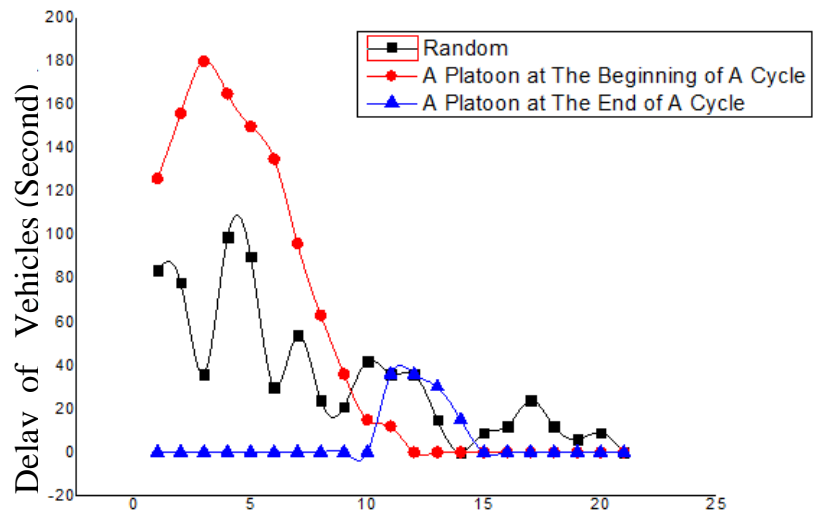

The Time Interval of a Cyle of Traffic Lights

Fig. 6. The delay of all vehicles. They arrive at the stop-line of traffic lights signal in a group of vehicles per time step. A time step is three seconds. The total sum of delay for all time steps is the delay of all vehicles in a cycle of a traffic light. The black pattern is for the vehicles that have a random arrival. Both the red and the blue patterns are for the vehicles that are arrived in the form of a group or platoon. For the red pattern, they arrive at the beginning of the traffic lights cycle. It is when the signal lights up red. For the blue pattern, they arrive when the traffic lights immediately turned green

Several assumptions and constants are used to obtain the results in Table 2. They are as the following. Its cycle is for 63 seconds. The traffic volume is $2,500 \mathrm{PCUs} /$ hour. The level of DS $<0.5$. It means that no vehicles remaining in queues of the previous traffic light cycle. The red, yellow, and green time intervals are $36,3,24$ seconds, respectively.

While it refers to Table 2, when a group/ platoon is formed, the travel delay becomes very high if they arrive when the red signal lights up. The Level of Service $(\mathrm{LoS})$ of the road dropped to D. The arrival of the group/ platoon dominant occurs when the signal lights up red. The arrival when the green signal is very minimal. However, this situation fluctuates. This is an uncertain situation. The same situation does not always occur again in the next traffic light cycle. But if this frequency is high, the level of traffic performance becomes worse. The reason is that because the travel delays increase to very high. This situation is certainly very uncomfortable for all road users.

Table 2. The Vehicles Delay For a Traffic Lights Cycle

\begin{tabular}{|c|c|c|c|c|}
\hline No & Arrival form & $\begin{array}{c}\text { The state of traffic lights while } \\
\text { they arrive }\end{array}$ & $\begin{array}{c}\text { Delay Average } \\
\text { (second/ PCU) }\end{array}$ & LoS \\
\hline 1. & Random & $\begin{array}{c}\text { Random } \\
\text { The Beginning of cycle (Early } \\
\text { of the red signal) }\end{array}$ & 29.8 & $\mathrm{C}$ \\
3. & Group/ Platoon & $\begin{array}{c}\text { Group/ Platoon } \\
\text { The end of the red signal and } \\
\text { ready for the green signal. }\end{array}$ & 3.1 & $\mathrm{~A}$ \\
\hline
\end{tabular}

The travel delay is close to zero if the group/ platoon come when the green signal is on. The level of service $(\mathrm{LoS})$ of the road is increased to A. The third situation usually occurs when the setting of the traffic lights at the adjacent intersection has been coordinated. This is usually applied in urban networks, where the location of the signalized intersection is in the adjacent area.

When the traffic light schedule of two intersections has not coordinated, an actual control system can be applied. While there is no vehicle passing in first 3 seconds time interval, the green signal will turn red at the fourth second. This must use many vehicular sensors. This method is effective to reduce travel delays. It is provided while the volume does not exceed road capacity. This method is also appropriate for implementation when congestion occurs.

The pattern for the red and black curves grows exponentially. Both occur if the schedule of traffic signals at the adjacent intersection does not have coordination. Based on the travel delay algorithm that is built, we can conclude that the signalling coordination schedule is very urgent, especially in the signalized intersections in urban areas that are close to each other. 


\subsection{The Device Required}

For future work, the additional device required that attached for every vehicle. A travel delay counters those actives while the vehicle's engine is on, but the vehicle is stopped. When the vehicle stops in front of a traffic light signal, the device must register its presence.

Based on Fig. 7., the registration on all vehicles. The delay of the non-stop vehicles is zero. Travel delay is counted on vehicles that come on each arm of the intersection. It uses wireless network technology.

In Fig. 8., There is a flowchart on a device installed in each vehicle. It is placed in a specific part of the vehicle body that is safe from distraction. It can transmit and receive signals over short distances. It must be able to interact with the device installed in each arm of the signalized intersection.

In Fig. 9., we present the flowchart on the device installed in each signalized intersection arm. It must be installed in a safe location and barrier-free area to interact with any vehicle at the arm of the intersection. It must be able to be active continuously during the day and night.

Indirectly, a vehicle's delay sensor can measure the performance of the trip carried out. The amount of fuel consumed, travel time, and distance can all be recorded to measure efficiency. When the vehicle stops at a long time interval, the device initializes. This is a precise measurement of many variables per travel. Using this device, the driver can assess his own travel, whether it is efficient or wasteful.

The Central Processing Unit (CPU), which acts as a sensor unit is installed, collects all passing vehicle data. These data are the type of vehicle qualification, the time starts to stop because of the red signal, and when the movement starts again.

Delay CPU presents the average delay of each traffic light cycle. This is the actual data of the travel delay of each traffic light cycle. When the value is high, a jam is occurring. Conversely, if the delay is low, this means that travel schedule settings using traffic lights are appropriate with the volume of vehicles passing. The low value of travel delay is an indicator of the success of coordinating traffic light schedules for several adjacent intersections in urban areas.
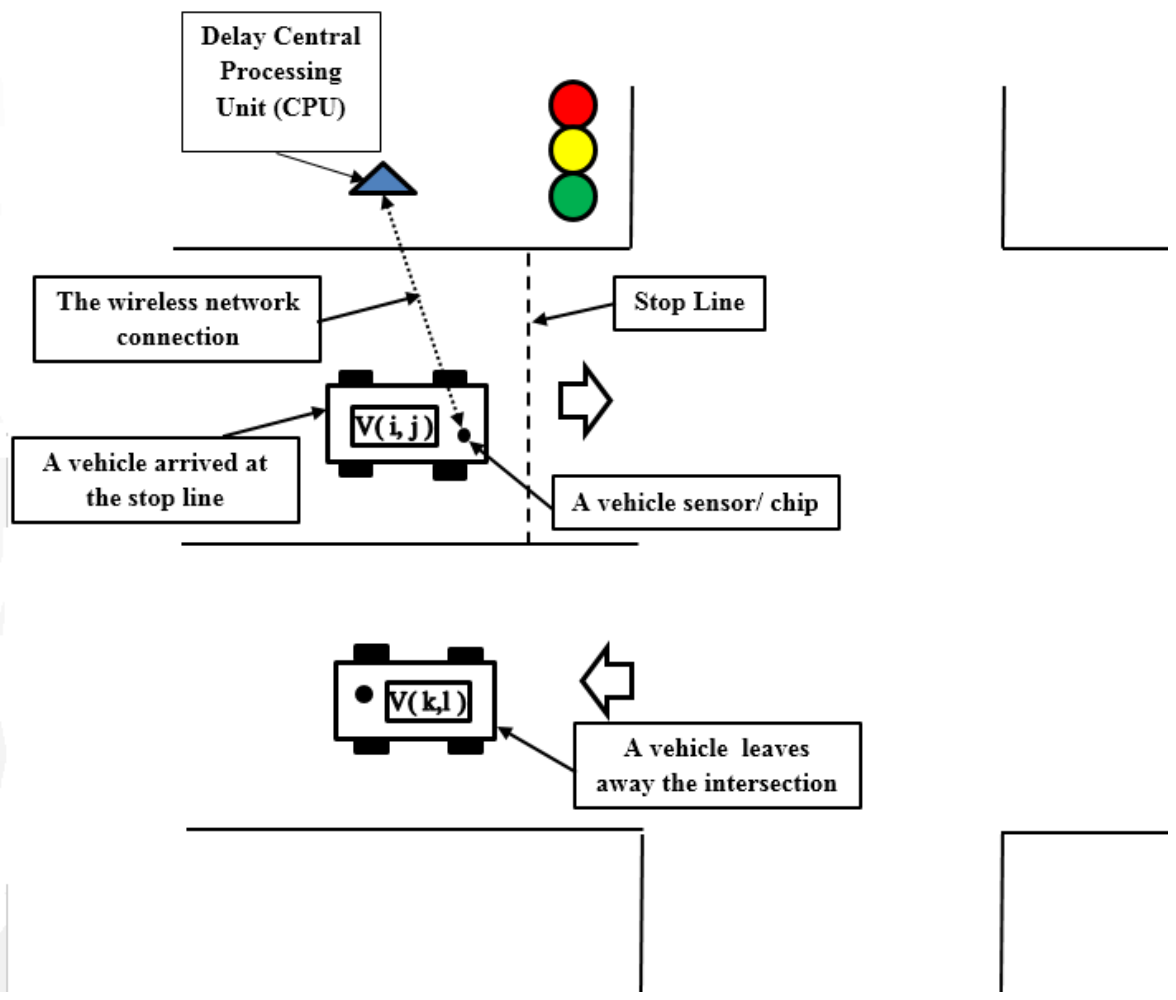

Fig. 7. An arm of an intersection. This is left-hand traffic. Each vehicle is accompanied by a sensor to measure its own delay. The delay sensor/microchip can communicate with delay CPU installed on the roadside. Both delay CPU and delay sensor, which has the shortest distance, can function as a data wireless transmitter and receiver. It is necessary to adjust the delay CPU location so that it is not ambiguous to measure the flow of vehicles from the other arm 


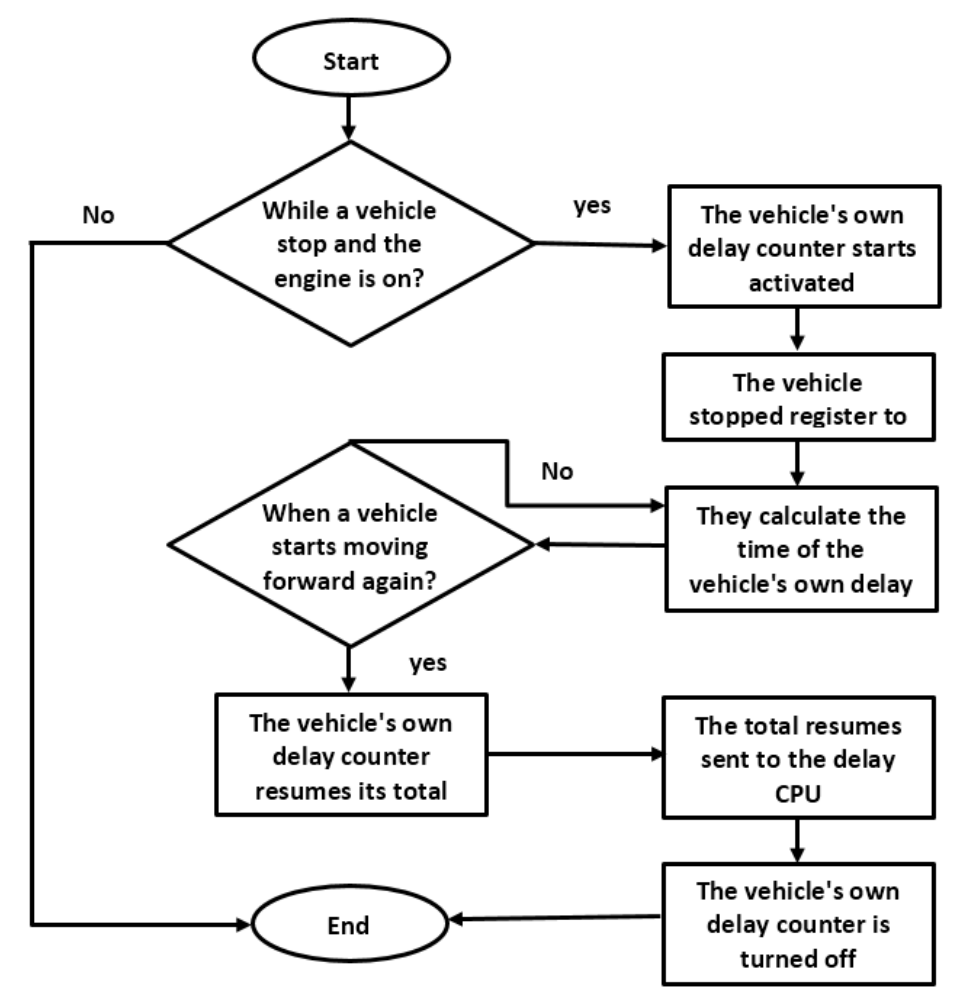

Fig. 8.The flowchart of a vehicle delay sensor activity

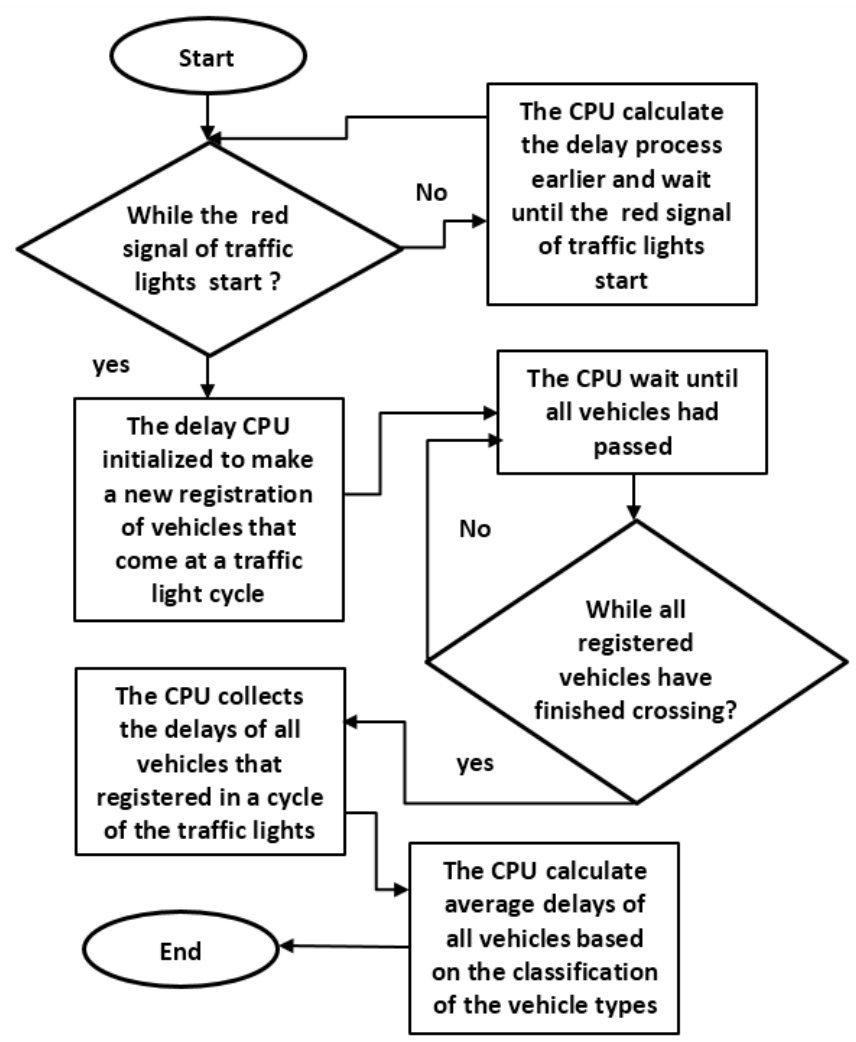

Fig. 9.The flowchart of the delay CPU activity

For the future, each vehicle must be equipped with a microchip. Lots of information can be stored in it. The location of the vehicle can be monitored at any time via satellite. This IoT-based system requires a satisfactory internet connection. Its implementation in a smart city cannot be partial but must be the totality. Of course, this requires a lot of experts on information systems and extra costs. Many benefits can be obtained if this can be a reality. But its weakness, the privacy space becomes very narrow. 


\section{CONCLUSION}

The result of the study has successfully described the travel delay in a high precision. The arrival of vehicles has been considered to have a normal pattern. The algorithm presents a vehicle queue with a discrete system. The arrival in a group/ platoon form at the beginning of the red signal causes the travel delay to be very high. In other words, when the traffic lights schedule has been coordinated to another adjacent intersection, the arrival in the form of groups/ platoons is always happens at the end of the red signal or when the green signal is on. While they are in the randomized arrivals, the travel delay is reflected in the middle of the group/ platoon that comes at the beginning and at the end of the red signal.

\section{ACKNOWLEDGMENTS}

The Ministry of Research, Technology and Higher Education of Republic Indonesia has funded this research in the PTUPT scheme in the year 2018.

\section{REFERENCES}

[1] https://nptel.ac.in/courses/105104098/TransportationII/lecture8/text/8\%20slide.html

[2] B. Seibold, A Mathematical Introduction to Traffic Flow Theory, Tutorials Traffic Flow, Temple University \& Institute for Pure and Applied Mathematics, UCLA, September 2015

[3] T. Tristono, "Study of Traffic Vehicles Delay on A Signalized Intersection Integrated to The Railway Doorstop", Journal Agritek, No. 1, vol. 15, University of Merdeka Madiun, pp. 81-91, March 2014.

[4] F. Viti and H. J. Van Zuylen, "Queues And Delays At Signals: A General Approach", Delft University of Technology, Department of Civil Engineering, Section Transport and Planning, Stevinweg 1, 2628CN Delft, The Netherlands, 2009

[5] N. Mufidah, "Modeling Of Motor Vehicle Queue Using M/M/1 Queue Models In Simpang Tiga Ringroad Utara Yogyakarta," Undergraduate Final Project, Statistics Department, Islamic University of Indonesia, Yogyakarta, 2018.

[6] M. Soares, "Architecture-Driven Integration of Modeling Languages for the Design of Software-Intensive Systems", The Thesis, Next Generation Infrastructures Foundation, Delft, Netherlands, pp. 99-133, February 2010.

[7] P. S. Djarwanto and P. Subagyo. Inductive Statistics. Edition 4, BPFE, Yogyakarta, 2000

[8] A. Narendra, and A. Budiwirawan, Studi Penanganan Tundaan Pergerakan di Persimpangan Empat Lengan Banaran-Sekaran, Jurnal Teknik Sipil \& Perencanaan, Universitas Negeri Semarang (UNNES), No. 1, Vol. 16, pp. 1 -14, January 2014.

[9] M. B. Asih, and I. Muthohar, Upaya Pemecahan Masalah Lalu Lintas Akibat Aktivitas Sisi Jalan yang Tinggi dengan Analisis Tundaan", The 15th FSTPT International Symposium, STTD Bekasi, November 23-24, 2012.

[10] O.Z. Tamin, Transport Planning \& Modeling, ITB Publisher, Bandung, 2000.

[11] ICHM, Indonesian Capacity Highway Manual, Directorate of Highways Directorate of Road Development City, Jakarta, 1997.

[12] R. Kurniawan and R. A. Al-Hasibi, The Concept of Adaptive Traffic Control that Synchronized with Density as Solutions to Minimize the Duration of the Waiting Time of Vehicles", Semesta Teknika, The Scientific Journal, No. 2, vol. 10, Faculty of Engineering, UMY, November, 2007, pp. 126-135.

[13] Alamsyah, A. Alik, Rekayasa Lalu Lintas, S. Amien (Ed), Malang, UMM. 2005.

[14] G. W. Hamidi, A. Frederika, \& P. K. Winaya, Travel Cost Analysis Due To Traffic Delays , Jurnal Ilmiah Elektronik Infrastruktur Teknik Sipil, Volume 2, No. 1, UNUD, Pebruari 2013.

[15] M. I.Mujahidin, A. Sumarsono, and S. J. Legowo, Hubungan Tundaan dan Panjang Antrian Terhadap Konsumsi Bahan Bakar Akibat Bottleneck pada Pembangunan Flyover Di Palur, e-Jurnal Matriks Teknik Sipil- UNS, Desember 2014. 
